\title{
Change Management and the Role of Leadership in Facilitating Organizational Change in Corporate Takeovers
}

\author{
Radu Florea, PhD Cand.
}

\begin{abstract}
Facilitating organizational change depends to a great extent on the ability of the management team to coordinate the amendments related to a recent merger with another organization or to the takeover of a medium-sized company by a multinational organization. Change management is one of the most discussed topics in the study of organizations; modern companies that are constantly subjected to significant changes in order to adapt to market requirements need a management capable of developing the capacity to solve atypical problems and improve performance across their enterprises. In this regard, change management is the organization's orientation towards continuous development to improve results. This paper focuses on explaining the managerial role in modern organizations through the conceptual definition of management and by defining the principal element in organizational implementation, namely leadership. An organization can be brought to a desired status - significantly different from the actual one- only through optimum management of the change process; change management can thus be represented as the process of adapting the organization to the requirements imposed by an outside entity - in this case, a multinational organization that requires a different set of rules and procedures. This can be achieved through the development of leadership skills in management, in order to facilitate the change process specific to any takeover or corporate merger. The paper seeks to circumscribe leadership as a central element in facilitating the transition of the organization by acquiring and retaining organizational commitment. The new directions of leadership research as a reference for conceptual change management is defined respectively as transformational leadership and transactional leadership (Riaz and Haider, 2010).
\end{abstract}

Keywords: change, management, leadership, facilitating, organizational, change, corporate, takeovers

\section{Introduction}

McCalman (2002) states that although organizational change is largely caused by external factors of the environment in which the organization functions, without the willingness to change of the company members, the change process can meet significant resistance. Thus, in order for a change process to be positively met, it needs to have a clear direction which can only be given by persons who are seen as leaders of the organization. The study of leadership in organizations is therefore considered to be the fundamental element in defining best practices with general application in improving change management. Lawler and Galbraith (1993) define the concept of change management as being the continuous focus on improvement, developing new technologies, processes and procedures that can help an organization achieve its full potential. In this regard, having a clear understanding of the way in which leadership can facilitate change management can provide further clarifications on how change processes can be deployed without resistance by company personnel.

This paper focuses on the role in which transformational leadership can facilitate the takeover of a medium East-European company with ownership from a single party by a multinational corporation. The main role of leadership - from a transformational perspective- is to reduce resistance to change and help an organization's personnel in reaching performance level desired by the new management. A corporate takeover implies that a lot of changes need to be considered for obtaining organizational performance according to the new standards. Surpassing the need for procedural changes, a corporate takeover needs to take into account the fact that people management is one of the key aspects needed in organizational change (Van de Veen \& Poole, 200). In this regard, one of the most discussed paradigms in the study discipline of organizational change is that of transformational leadership ( Bass, 1995). 


\section{Transformational and transactional leadership- theoretical framework}

The leadership types that are agreed by most theorists to be sought as being desirable during a change process are transactional and transformational leadership (Aarons, 2006). Transactional leadership, as defined by Kuhnert and Lewis (1987), is based on the statement that the concept of leadership is mostly focused on relationships - transactions- in order to facilitate the change process. By improving the ways in which relationships are developed in a corporate takeover implies that resistances to change will be diminished. Nurturing transactional leadership can lead to an increase in collaboration. Transformational leadership relies on specific behavioral patterns of the leaders that can influence the performance levels of their followers (Avolio \& Yammarino, 2002). Taking into account the fact that an organizational change process is mainly based on the dynamics between the corporate entity and the company's personnel, facilitating the relationship between these two parties can only be done by members of the organization that have a leader status (formal or informal) in the company. This paper is centered on the aforementioned leadership models (transformational and transactional) and the way in which they can help companies assimilate a new value system, a new organizational culture and a clear viewpoint on organizational effectiveness. Relationships between a leader and his followers can be pragmatic and emotional, as stated by Burns (1978). A pragmatic relationship between a leader and his followers refers to an agreement to which both parties agree upon that concerns handling specific tasks. The key aspect in diagnosing the pragmatic dimension of transactional leadership is agreement between both parties. A consistent level of agreement between a leader and his followers represents the baseline needed for developing a positive relationship and a high quality transaction at an interpersonal level between the two parties (Avolio \& Yammarino, 2013). The emotional dimension of transactional leadership is based on understanding the importance of the role of each employee in the organization, by accepting and being aware of the current status of the transition process that is currently being deployed in the company.

Transactional leadership can only be manifested in a transactional culture (Bass, 1993). In order for an organization that is undergoing a corporate takeover to develop a transactional culture the key value that needs to be promoted in the company needs to be the improvement of high quality relationships. A transactional culture implies short-term rewards, due to the fact that positive relationships between peers can influence their perception on the organization and implicitly the corporate takeover that is ongoing. Also, assessing the perks that a leadership model based on transaction can have we can state that most scenarios in which it can be truly helpful refer to surpassing punctual resistances to change (Avolio \& Yammarino, 2013). Nonetheless, a transactional culture based on transactional leadership is not sufficient for maintaining a smooth transition to a desired state on a long term. Bass (1993) states that in order for an organizational culture to truly be helpful in a change process it has to be focused on transforming the organization and not only on improving the status of the relationships that members of the organization have. The highlight of this particular statement is that in order for an organization to be capable of transforming from a cultural point of view - as in the case discussed in this paper-, encouraging a leadership model based on relationship optimization is mandatory but not sufficient. Corporate takeovers or transformations -as seen by Bass- need to change the core of the organization and with it the entire functioning apparatus of the company. Bass also states that a transformational culture encourages long standing commitment, as opposed to a transactional culture which is supposed to have a short term impact on the commitment levels of employees.

The most relevant method for assessing if an organizational culture is mostly transactional or transformational is the ODQ (Organizational Description Questionnaire) assessment instrument, composed by 28 indicators that diagnose if the cultural style is transactional or transformational and what kind of leadership style perceived by employees (Bass, 1993). A lower score of the questionnaire elements that relate to transactional culture indicators imply that the organizational culture is regarded as being of a transformative nature. Also, the key element that defines de ODQ is the leadership perspective. As a descriptive instrument the ODQ highlights leadership features and categorizes them in transactional and transformational according to its methodology. By combining the scores for both dimensions (transactional and transformational) the ODQ lists several possible cultural type in accordance to different transformational leadership levels (Bass,1993):

Predominantly transformational culture

High contrast culture - characterized by both high transformational leadership scores and also high transactional leadership scores 
Coasting organizational culture- neither transformational or transactional, a coasting organizational culture is positioned and the middle of both scales of the ODQ

Predominantly to moderate contractual organizational culture- cultures that are considered to lack transformational elements and mainly focus on transactional aspects

Pedestrian cultures- a type that has moderate scores of transactional leadership and low scores on the elements regarding transformational leadership

Garbage can organizational culture- a culture type that has low scores both on transformational and transactional leadership

\section{Main differences between transactional and transformational leadership}

Bass (1985) identified a number of skills that differentiate transactional leadership from transformational leadership. His assumption was that leaders are depending on their personal traits and abilities. Considering this approach, substantial differences between transactional leadership and transformational leadership can be highlighted, as seen below:

A transformational leadership typology relies on a few essential abilities such as: charisma, inspiration, intellectual stimulation and individual appreciation (Bass, 1985). According to this framework transformational leadership can only be present in organizations that have leaders which express these abilities. Bass defines them as abilities that can be identified by specific behaviors:

Charisma: a leader that expresses this ability will provide vision and a sense of belonging, inspiring confidence and earning the respect of employees

Inspiration: a leader that inspires will communicate his expectations, and focus the effort of his employees to specific goals expressed in a simple manner

Intellectual stimulation: as a transformational leadership characteristic intellectual stimulation relies on a leader's capacity to develop problem solving abilities among his employees, by promoting autonomy and by encouraging responsibility

As previously stated, transactional leadership relies on the concept of relationship improvement; therefore, focusing a change process on transactional leadership cannot have a definitive impact on defining a new status for a company. A general agreement in most of organizational paradigms is that the role of transformational leadership is essential in high end organizational changes. A few general characteristics that define transactional leadership focus on abilities such as:

Rewards: financial or nonfinancial

The verification of deviations from a specific procedure only when the quality standards of the company are not met

Interventions from managers only when high end objectives are affected

Having the concept of high quality relationships as a focal point for transactional leadership is the main point from which it can be deduced that transactional leadership cannot function in an alert organizational change as a corporate takeover. As stated by Bass (1990), transformational leadership is an ability that needs to be present in any change context in order for it to be a successful transition. He also states that the most important aspect required for a manager is charisma; a charismatic manager can very easily influence others, by inspiring confidence in a specific direction.

One of the most important aspects of transformational leadership is the capacity to divide a change process in "change areas" (Matthews, 2010) as opposed to transactional leadership which focuses on one specific feature which is the development of high quality relationships. A transformational leadership perspective focuses on a plan that means to have a significant impact not only on relations that occur in an organizational context but also on processes, procedures, values and other aspects of the organizational environment.

The fundamental difference between the two leadership types is basically that transformational leadership is focused on long term improvement -with focus on developing positive organizational cultures-compared to the transactional leadership 
which is mostly based on maintaining a level of cohesion among the company personnel. Finally, the difference between the two can be viewed as the difference between the concept of organizational development compared to the idea of maintaining organizational efficiency at a current level.

\section{Applicability of transformational leadership in improving organizational performance - a qualitative case study on customized models of behavior for transformational leaders -}

The presence of transformational leadership in corporate takeovers was studied through two focus groups in a company activating in the automotive industry, totaling 280 employees; the company was recently taken over by a multinational corporation with plans of rapid expansion on the market. Employees were informed of the goals regarding company growth which involved doubling the organizations turnover within a year and implementing two new technologies. As it was expected by the corporation, the changes were met with resistance by the company's employees. In this regard, this study aims at assessing what are the main aspects which employees consider necessary for a manager to have in an organizational change context.

The focus groups consisted of 12 people each and had a duration of approximately 2 hours and 30 minutes, in which discussions were moderated concerning management abilities which the company personnel thought as being relevant for the change context resulted from the corporate takeover. Discussions were focused on the Organizational Description Questionnaire 28 indicators; participants were asked to express their opinion regarding their importance and their presence in company's current change context. The main topics of discussions were:

The importance of negotiations with management regarding process improvement

How employee initiative is viewed by company management

How are rewards perceived by employees

Do managers admit their mistakes, and if so how are they handled

The degree in which managers encourage proactive behaviors

Acknowledgment of company values and objectives by all personnel

The first focus group was formed by 12 employees from the production department occupying various positions such as line management, team management and line management. The principal aspects that were highlighted in the focus group concerned the pressure from management and the lack of equity in recognizing individual contribution in achieving organizational objectives. Relevant quotes from employees extracted from the transcripts are as follows: "The pressure felt from management is overwhelming and it affects our performance; I believe that it will be very difficult to achieve our current objectives; I don't think that my work is valued by company management".

A clear differentiation from the old company standards is felt by employees after the takeover; also, employees from the production department do not believe the management team is focusing on the changes that are needed in order for the team to adapt to the new company objectives. In this regard, an absence of any transformational leadership ability - as it is felt by production personnel- can induce a high level of resistance to change from employees. They also state that in order for the company to function optimally there is a need of relevant, sustainable leadership based on recognition, charisma and innovation. Employees believe that if the management team does not focus on improving the current working methods the degree of satisfaction and commitment to the company will be decreased. Also, employees do not feel they have an understanding of the company culture and long term mission. Finally, employees believe that the management team is concerned on transforming the organization only from a procedural perspective without a clear interest in optimizing the production workflow and on addressing employee needs.

The second focus group was formed by members from the quality department which believe that the takeover helped them in developing their competencies and in improving their working methodologies. Participants stated that the company invested in the quality department and that their commitment to the company increased, as well as their level of satisfaction. "I believe that the past few months have been essential to my professional development; The investment in this company is highly appreciated by all personnel; Not only professional aspects of our job we're improved, but also the clarity on how we need to function as a singular entity;" we're only some of the statements resulted from the focus group. 
Differences exist regarding employee perception on the takeover but also on the way in which the company is managed. Employees from the quality department perceive the company as having a positive trend of growth and development and are satisfied on the organization's leadership. Differences from the two focus groups highlight the fact that even if transformational leadership is clearly wanted by the company, it is not necessarily felt by employees as a positive aspect. The fact that employees tend to have different perceptions based on the departments in which they work can be viewed as a clear indicator of disproportionality in the way in which change is implemented by management. Having a good understanding on the change necessity, the management of the quality department focused on the key elements that we're important for employees, thus having a high degree of success in the implementation of change. Employees from the production department are feeling a very high pressure for achieving tasks that to them seem to be unachievable. In this regard we can state that if management is not directly involved in achieving targets, in early phases of the organizational change it can be met with high resistance from the company personnel.

Also, even if the company communicates its vision, mission and values at top management level, there is a very clear need for transformational leadership abilities in order for all personnel to be aware of the upcoming changes that are to be implemented. In absence of these abilities from some members of the management team, the impact that a corporate takeover might have on the company personnel will be met with resistance, as previously stated. The concept of customized transformational leadership abilities is derived from the differences identified in the focus groups. Furthermore, tailored leadership abilities on each department may have a higher impact on reducing resistance to change, considering the fact that at departmental levels organizational change is felt differently and transformational leadership capabilities may have higher impact consequently.

\section{Conclusions}

This paper tried to emphasize the importance of leadership in organizational change context, by discussing the two main dimensions that define leadership in modern organizations, namely transactions and transformations. As it was previously mentioned, a general competency model for transformational leaders cannot encompass the mandatory features in order for resistance to change to be diminished. By framing a clear need for the presence of transformational leadership abilities in corporate takeovers it needs to be stated that a functional competency model for transformational leaders can only be highlighted by studying company needs and customizing development programs for each manager, at departmental level.

\section{References}

[1] Avolio, B and Yammarino, F, 2013, Transformational and charismatic leadership: the road ahead, NYBinghamton

[2] Bass, B and Avolio, B, 1993, Transformational Leadership and Organizational Culture, Suny- Binghamton

[3] Bass, B, 1985, Leadership and performance beyond expectations, New York: Free Press

[4] Bass, B, 1993, Handbook of Leadership, New York: Free Press

[5] Bass, B.M. \& Avolio, B.J. (Eds.). (1994). Improving organizational effectiveness through transformational leadership. Thousand Oaks, CA: Sage Publications

[6] Burns, J. 1978, Leadership, New York, Harper-Row

[7] Lawler, E. and Galbraith, J, 1993, Organizing for the future: the new logic for managing complex organizations, Josey-Brass, San Francisco

[8] McCalman, J. and Lory, M, 2002, Management consultancies as brands: Can David learn from Goliath?, The Journal of Brand Management, p.412-429

[9] Poole, M., Van de Veen, A., Dooley, K. \& Holmes, M. 2000, Organizational Change and Innovation Process, Oxford University Press, Oxford, England.

[10] Riaz, A. and M.H. Haider, 2010. Role of transformational and transactional leadership on job satisfaction and career satisfaction. Bus. Econ Horiz

[11] Singh, Bhupinder, 2008, Organizational commitment Revisited, Journal of the Indian Academy of Applied Psychology, Vol. 34, No.1, 57-68 